\title{
PENGARUH KOMUNIKASI DAN LINGKUNGAN KERJA FISIK TERHADAP KINERJA KARYAWAN
}

\author{
Indah Choirun Nisa, Rooswidjajani, Yuntawati Fristin \\ Universitas Merdeka Malang \\ Email : Indahchoirunnisa245@gmail.com
}

\begin{abstract}
The objective of this research is to analyst and explain the significant effect of Communication on Employees Performance, analyst and explain the significant effect of Physical Work Environmental on employees Performance and analyst and explain the effect of Communication and Physical Work Environmental on employees simultaneously and dominant variable. Population in this researcrh is all of employees of PT. PLN (Persero) Area Malang Rayon Malang Kota which is 40 respondents, saturated sampling technic method to analysis the research, saturated sampling is the the count of sample is all of population member, which is is 40 responden. Multiple regression analysis. The result shows that Communication have positive significant effect on Employees Performance, Physical Work Environmental have positive significant effect on Employees Performance, Communication and Physical Work Environmental simultaneously have significant effect of employees performance, Communication have dominant effect for employees performance of the Physical Work Environmental.
\end{abstract}

\section{Keyword : Communication, Physical Work Environmental and Employees Performance}

\begin{abstract}
Abstrak : Tujuan penelitian untuk menganalisis dan mengetahui pengaruh signifikan variabel komunikasi terhadap kinerja karyawan, menganalisis dan mengetahui pengaruh signifikan lingkungan kerja terhadap kinerja karyawan dan mengetahui dan menganalisis pengaruh komunikasi dan lingkungan kerja secara simultan terhadap kinerja karyawan serta variabel yang paling dominan. Populasi dalam penelitian ini adalah seluruh karyawan PT PLN Rayon Malang Kota sebanyak 40 responden. Teknik sampling yang digunakan dalam penelitian ini adalah teknik sampling jenuh atau sensus, yaitu penetapan jumlah sampel dari seluruh anggota populasi yaitu 40 responden. Alat analisis yang digunakan adalah analisis regresi linier berganda. Hasil penelitian menunjukkan bahwa Komunikasi memiliki pengaruh signifikan positif terhadap Kinerja karyawan, Lingkungan Kerja memiliki pengaruh signifikan positif terhadap Kinerja karyawan, Secara simultan (bersama-sama) Komunikasi dan Lingkungan Kerja berpengaruh signifikan terhadap Kinerja karyawan, Komunikasi memiliki pengaruh dominan terhadap kinerja karyawan dibandingkan lingkungan kerja.
\end{abstract}

Kata Kunci: Komunikasi, Lingkungan Kerja dan Kinerja Karyawan. 


\section{PENDAHULUAN \\ Latar Belakang}

Kinerja karyawan sangat dipengaruhi beberapa faktor antara lain kepemimpinan, komunikasi, Lingkungan kerja, pemberian motivasi, dan kepuasan kerja karyawannya. Jika salah satu faktor saja kurang diperhatikan akan memepengaruhi kinerja karyawan pada organisasi/perusahaan dimana mereka bekerja, dalam hal ini tentu berdampak pada tujuan perusahaan/organisasi. Karyawan yang berkualitas sangat dibutuhkan oleh perusahaan agar perusahaan dapat maju dan berkembang, karyawan yang berkualitas merupakan karyawan yang memiliki kinerja yang baik dan dapat memenuhi target atau sasaran perusahaan, upaya perusahaan untuk mendapatkan karyawan yang berkualitas yakni dengan melakukan penerapan kinerja. Selain faktor komunikasi dalam organisasi faktor lingkungan kerja merupakan hal penting yang harus diperhatikan, yang dimaksud lingkungan kerja disini adalah lingkungan fisik yang meliputi sarana dan prasana dan kerja non fisik yang meliputi suasana kerja dan hubungan kerja.

\section{Tujuan Penelitian}

Sesuai dengan judul yang ada, maka tujuan penelitian ini untuk mengetahui:

1. Untuk mengetahui dan menganalisis pengaruh secara signifikan variabel komunikasi terhadap kinerja karyawan di PT PLN (Persero) Tbk. Area Malang Rayon Malang Kota.

2. Untuk mengetahui dan menganalisis pengaruh signifikan lingkungan kerja fisik terhadap kinerja karyawan di PT PLN (Persero) Tbk. Area Malang Rayon Malang Kota.

3. Untuk mengetahui pengaruh simultan variabel komunikasi, lingkungan kerja fisik terhadap kinerja karyawan di PT PLN (Persero) Tbk. Area Malang Rayon Malang Kota.

4. Untuk mengetahui pengaruh dominan variabel komunikasi, lingkungan kerja fisik terhadap kinerja karyawan di PT PLN (Persero) Tbk. Area Malang Rayon Malang Kota.

\section{TINJAUAN PUSTAKA}

Komunikasi

Menurut Handoko

(2012:272)

Komunikasi adalah "Proses pemindahan pengertian dalam bentuk gagasan atau informasi dari seseorang ke-orang lain". Dalam perpindahan pengertian tersebut tidak hanya sekedar kata-kata yang digunakan dalam sebuah percakapan, tetapi juga dibutuhkan ekspresi wajah, intonasi, titik putus vokal dan lain sebagainya. Menurut Suranto (2010) , ada beberapa indikator komunikasi efektif, ialah :

a. Pemahaman

Pemahaman Ialah kemampuan memahami pesan secara cermat sebagaimana dimaksudkan oleh komunikator.

b. Kesenangan

Apabila proses komunikasi itu selain berhasil menyampaikan informasi, juga dapat berlangsung dalam suasana yang menyenangkan ke dua belah pihak..

c. Pengaruh pada sikap

Tujuan berkomunikasi adalah untuk mempengaruhi sikap. Jika dengan berkomunikasi dengan orang lain, kemudian terjadi perubahan pada perilakunya,

d. Hubungan yang makin baik

Bahwa dalam proses komunikasi yang efektif secara tidak sengaja meningkatkan kadar hubungan interpersonal. Seringkali jika orang telah memiliki persepsi yang sama, kemiripan karakter, cocok, dengan sendirinya hubungan akan terjadi dengan baik.

e. Tindakan

Komunikasi akan efektif jika kedua belah pihak setelah berkomunikasi terdapat adanya sebuah tindakan..

\section{Lingkungan Kerja}

Lingkungan kerja menurut Sedarmayanti (2009:21) adalah keseluruhan alat perkakas dan bahan yang dihadapi, lingkungan sekitarnya di mana seseorang bekerja, metode kerjanya, serta pengaturan kerjanya baik sebagai perseorangan maupun sebagai kelompok. Berikut ini beberapa indikator yang diuraikan Sedarmayanti (2009:28) yang dapat mempengaruhi terbentuknya suatu kondisi lingkungan kerja :

1. Penerangan/cahaya di tempat kerja

Cahaya atau penerangan sangat besar manfaatnya bagi karyawan guna

mendapat keselamatan dan kelancaran kerja, oleh sebab itu perlu diperhatikan adanya penerangan (cahaya) yang terang

2. Sirkulasi udara di tempat kerja Oksigen merupakan gas yang dibutuhkan oleh makhluk hidup untuk menjaga 
kelangsungan hidup, yaitu untuk proses metabolisme. Udara di sekitar dikatakan kotor apabila kadar oksigen dalam udara tersebut telah berkurang dan telah bercampur dengan gas atau bau-bauan yang berbahaya bagi kesehatan tubuh. Sumber utama adanya udara segar adalah adanya tanaman disekitar tempat kerja. Tanaman merupakan penghasil oksigen yang dibutuhkan oleh manusia.

3. Kebisingan di tempat kerja

Salah satu polusi yang cukup menyibukkan para pakar untuk mengatasinya adalah kebisingan, yaitu bunyi yang tidak dikehendaki oleh telinga..

4. Bau tidak sedap ditempat kerja

Adanya bau-bauan di sekitar tempat kerja dapat dianggap sebagai pencemaran, karena dapat mengganggu konsentrasi bekerja,

5. Keamanan di tempat kerja

Guna menjaga tempat dan kondisi lingkungan kerja tetap dalam keadaan aman maka perlu diperhatikan adanya keamanan dalam bekerja.

\section{Kinerja}

Hariandja (2002 : 195) menyatakan bahwa kinerja merupakan perilaku nyata yang ditampilkan sesuai dengan perannya dalam organisasi dan kinerja merupakan suatu hal yang sangat penting dalam usaha organisasi untuk mencapai tujuannya. Indikator kinerja dalam penelitian ini adalah sebagai berikut:

1. Kuantitas, diukur dari persepsi karyawan terhadap jumlah aktivitas yang ditugaskan beserta hasilnya.

2. Kualitas, dapat diukur dari persepsi karyawan terhadap kualitas pekerjaan yang dihasilkan serta kesempurnaan tugas terhadap ketrampilan dan kemampuan karyawan. Hasil pekerjaan yang dilakukan mendekati sempurna atau memenuhi tujuan yang diharapkan dari pekerjaan tersebut.

3. Ketepatan waktu, diukur dari persepsi karyawan terhadap suatu aktivitas yang diselesaikan dari awal waktu sampai menjadi output. Dapat menyelesaikan pada waktu yang telah ditetapkan serta memaksimalkan waktu yang tersedia untuk aktivitas yang lain.

4. Efektifitas, pemanfaatan secara maksimal sumber daya dan waktu yang ada pada organisasi untuk meningkatkan keuntungan dan mengurangi kerugian.
5. Kehadiran, tingkat kehadiran karyawan dalam perusahaan dapat menetukan kinerja karyawan.

\section{Model Penelitian}

Berdasarkan tinjauan pustaka serta tinjauan empiris yang telah dipaparkan sebelumnya serta, maka peneliti menyusun model penelitian sebagai berikut:

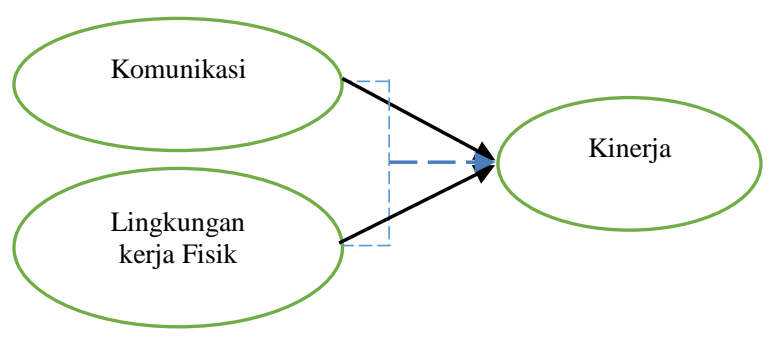

\section{Hipotesis Penelitian}

Hipotesis penelitiaan adalah jawaban sementara terhadap rumusan masalah penelitian, di mana rumusan masalah penelitian telah dinyatakan dalam bentuk pertanyaan. Dikatakan sementara karena jawaban yang diberikan baru didasarkan pada teori (Sugiyono, 2014:96) dan dalam penelitiaan ini sebagai berikut :

1. Diduga bahwa tidak ada pengaruh simultan antara variabel komunikasi dan lingkungan kerja fisik terhadap variabel kinerja karyawan PT. PLN (Persero) Tbk. Area Malang Rayon Malang Kota.

2. Diduga bahwa ada pengaruh secara signifikan antara variabel komunikasi terhadap variabel kinerja karyawan di PT. PLN (Persero) Tbk.Area Malang Rayon Malang Kota.

3. Diduga bahwa ada pengaruh secara signifikan antara variabel lingkungan kerja fisik terhadap variabel kinerja karyawan di PT. PLN (Persero) Tbk. Area Malang Rayon Malang Kota.

4. Diduga bahwa ada pengaruh simultan antara variabel komunikasi dan lingkungan kerja fisik terhadap variabel kinerja karyawan PT. PLN (Persero) Tbk. Area Malang Rayon Malang Kota.

5. Diduga bahwa ada pengaruh dominan antara variabel komunikasi dan lingkungan kerja fisik terhadap variabel kinerja karyawan PT. PLN Tbk. (Persero) Area Malang Rayon Malang Kota. 


\section{METODE PENELITIAN}

Metode yang digunakan dalam penelitiaan ini menggunakan pendekatan kuantitatif. Penelitian kuantitatif merupakan salah satu jenis penelitian yang spesifikasinya adalah sistematis, terencana dan terstruktur dengan jelas sejak awal hingga pembuatan desain penelitiaanya.

Populasi adalah wilayah generasi yang terdiri dari obyek atau subyek yang mempunyai kuantitas tertentu yang ditetapkan oleh penelitian untuk dipelajari dan kemudian ditarik kesimpulannya (Sugiyono:2014). Populasi pada penelitian ini adalah seluruh karyawan divisidivisi yang ada pada PT. PLN (Persero) Tbk. Area Malang Rayon Malang Kota yang berjumlah 40 orang.

Menurut Sugiyono (2014:116) "Sampel adalah sebagian dari jumlah dan karakteristik yang dimiliki oleh populasi, penentuan sebuah sampel harus dipilih sedemikian rupa sehingga setiap satuan elemeter mempunyai kesempatan dan peluang yang sama untuk dipilih" dalam penelitiaan ini berjumlah 40 orang

Uji validitas digunakan untuk mengukur sah atau tidak suatu kuesioner. Suatu kuesioner dikatakan valid jika pertanyaan atau pernyataan pada kuesioner mampu mengungkapkan sesuatu yang akan diukur oleh kuesioner tersebut. Ghozali (2013:53).

Uji reliabilitas merupakan alat untuk mengukur suatu kuesioner yang merupakan Indikator dari variabel atau konstruk. Suatu kuesioner dikatakan reliabel atau handal jika jawaban seseorang terhadap pernyataan adalah konsisten atau stabil dari waktu ke waktu (Ghozali, 2013:47)

\section{HASIL PENELITIAN Sejarah PT PLN}

Pemerintah Indonesia dalam mengelola dan mengembangkan kelistrikan di seluruh Indonesia diserahkan kepada PLN. Adapun Wilayah kerja PLN seluruh Indonesia terdiri dari 63 (enam puluh tiga) unit induk, 49 (empat puluh sembilan) unit bisnis induk, 6 (enam) anak perusahaan dan 8 (delapan) Direktorat dan 297 (dua ratus sembilan puluh tujuh) unit pelaksana, kesemuanya mempunyai tugas dan tanggung jawab masing-masing mulai dari Pembanggunan, Pembangkitan, Penyaluran dan pelayanan. Sebagai Contoh Propinsi Jawa Timur Unit induk Bisnis PLN sebutanya adalah Kantor

\section{Pengaruh Komunikasi terhadap Kinerja Karyawan}

Berdasarkan hasil uji t dengan tingkat signifikasi 0,05 atau $5 \%$. Kriterianya, $\mathrm{H}_{0}$ ditolak dan H1 diterima sehingga dapat disimpulkan terdapat pengaruh secara parsial antara variabel komunikasi (X1) terhadap kinerja (Y), hal ini ditunjukkan dengan hasil pengujian uji $\mathrm{t}$ yaitu $\mathrm{t}_{\text {hitung }} 4,541 \geq 1,684 \mathrm{t}_{\text {tabel }}$. Hal ini menyatakan bahwa semakin tinggi komunikasi atau semakin baik komunikasi maka kinerja karyawan di PT. PLN (Persero) Tbk. Rayon Malang Kota juga akan semakin meningkat atau baik.

\section{Pengaruh Lingkungan Kerja Fisik terhadap Kinerja Karyawan}

Berdasarkan hasil uji t dengan tingkat signifikasi 0,05 atau $5 \%$. Kriterianya, $\mathrm{H}_{0}$ ditolak dan $\mathrm{H} 1$ diterima sehingga dapat disimpulkan terdapat pengaruh secara parsial antara variabel lingkungan kerja Fisik (X2) terhadap kinerja (Y), hal ini ditunjukkan dengan hasil pengujian uji $t$ yaitu $t_{\text {hitung }} 3,344 \geq 1,684 \mathrm{t}_{\text {tabel. }}$. Hal ini menyatakan bahwa semakin baik lingkungan kerja di PT. PLN (Persero) Tbk. Rayon Malng Kota maka akan semakin baik pula atau meningkat kinerja karyawannya, hal ini juga didukung dengan pendapat Saydam (2005) juga menyebutkan bahwa lingkungan kerja merupakan keseluruhan sarana dan prasarana kerja yang ada di sekitar karyawan yang sedang melakukan pekerjaan yang dapat mempengaruhi pelaksanaan kinerja. Lingkungan kerja yang memadai akan berdampak baik terhadap peningkatan kinerja, sebaliknya lingkungan kerja yang tidak memadai dapat menurunkan kinerja karyawan.

\section{Pengaruh Komunikasi dan Lingkungan Kerja terhadap Kinerja Karyawan}

Berdasarkan hasil uji analisis statistik dengan menggunakan analisis linear berganda pada uji $F$ pada tingkat signifikasi 0,05 atau 5\%. Dapat diketahui bahwa H1 bahwa terdapat pengaruh simultan dari variabel komunikasi (X1) dan lingkungan kerja fisik (X2) terhadap Kinerja (Y). hal ini ditunjukkan dengan hasil perhitungan $\mathrm{F}_{\text {hitung } 27,788} \geq 3,232 \quad \mathrm{~F}_{\text {tabel }}$ dan signikasi 0,05 sehingga keputusannya $\mathrm{H} 1$ diterima dan $\mathrm{H}_{0}$ ditolak. Kinerja adalah hasil kerja yang dicapai oleh karyawan dalam melaksanakan tugas yang diberikan kepadanya sesuai dengan kriteria penilaian yang ditetapkan. Hasil kerja tersebut dapat meningkat karena adanya komunikasi yang baik dan efektif antar 
karyawan maupun atasan yang mempu mempengaruhi karyawan untuk bekerja lebih baik.

\section{Pengaruh secara Dominan} Berdasarkan

Unstandardized

Coefficients (B) pada hasil uji regresi linear berganda variabel komunikasi memiliki nilai Beta tertinggi yakni 0,524 dari pada lingkungan kerja yang memiliki nilai beta 0,386 . Hal ini menyatakan bahwa variabel komunikasi memiliki nilai tertinggi dari pada variabel lainnya

\section{KESIMPULAN}

Berdasarkan hasil analisis yang telah dilakukan dapat ditarik kesimpulan sebagai berikut :

1. Berdasarkan perhitungan analisis deskriptif diketahui bahwa rata-rata dari masingmasing perhitungan variabel Komunikasi (X1), Lingkungan Kerja (X2), dan Kinerja (Y) mayoritas responden setuju akan pelaksanaannya. Hal ini ditunjukkan dengan hasil grand mean keseluruhan berada diinterval >3-4 yang menyatakan positif (kuat), yang berarti PT. PLN (Persero) Tbk. Area Malang Rayon Malang Kota dalam hal komunikasi, lingkungan kerja dan kinerja sudah baik.

2. Komunikasi (X1) memiliki pengaruh yang signifikan terhadap kinerja karyawan (Y). hal ini ditunjukkan dengan hasil perhitungan $t_{\text {hitung }} \geq t_{\text {tabel }}$ dengan signifikasi 0,05 sehingga $\mathrm{H} 1$ diterima dan $\mathrm{H}_{0}$ ditolak.

3. Lingkungan kerja fisik (X2) memiliki pengaruh yang signifikan terhadap kinerja karyawan (Y). hal ini ditunjukkan dengan hasil perhitungan $t_{\text {hitung }} \geq t_{\text {tabel }}$ dengan signifikasi 0,05 sehingga $\mathrm{H} 1$ diterima dan $\mathrm{H}_{0}$ ditolak.

4. Pengaruh komunikasi (X1) dan lingkungan kerja fisik (X2) berpengaruh secara simultan terhadap kinerja karyawan (Y) di PT. PLN (Persero) Tbk Rayon Malang Kota hal ini ditunjukkan dengan hasil uji $\mathrm{F}$ dengan hasil $F_{\text {hitung }} \geq \mathrm{F}_{\text {tabel }}$ dan signifikasi 0,05 sehingga $\mathrm{H} 1$ diterima dan $\mathrm{H}_{0}$ ditolak.

5. Komunikasi (X1) berdasarkan Unstandardized Coefficients (B) pada hasil uji regresi linear berganda memiliki nilai tertinggi dari pada variabel lainnya, hal ini dapat dikatakan bahwa komunikasi (X2) berpengaruh dominan kinerja karyawan di PT. PLN Rayon Malang Kota.

\section{SARAN}

Berkaitan dengan hasil penelitian yang dilakukan terdapat beberapa saran-saran kepada PT. PLN (Persero) Tbk. Rayon Malang Kota :

1. Dengan melihat analisis deskriptif komunikasi dan lingkungan kerja fisik terhadap kinerja yang sudah baik hendaknya perusahaan menjaga komunikasi diwujudkan dengan acara gathering atau rapat mingguan untuk menjalin agar komunikasi tetap baik dan lingkungan kerja fisik yang sudah tersedia diperusahaan tetap dijaga dan diperbaiki atau diganti ketika rusak agar karyawan tetap nyaman dan kinerja karyawan semakin meningkat.

2. Program CoC (Code of Conduct) merupakan kegiatan sharing yang dilakukan karyawan dan manager untuk mendiskusikan program-program dari pusat, masalah-masalah yang terjadi antar karyawan. Hal ini perlu dilakukan dengan rutin agar komunikasi antar karyawan dengan karyawan maupun atasan tetap terjaga dalam bekerja agar tidak menghambat kinerja di perusahaan jika terjadi masalah terutama di PT. PLN (Persero) Tbk. Area Malang Rayon Malang Kota

3. Lingkungan kerja Fisik yang dilakukan PT. PLN Area Malang Rayon Malang Kota hendaknya dilakukan perawatan secara konsisten untuk menjaga lingkungan kerja fisik diperusahaan agar terus baik tidak hanya menunggu jika ada inspeksi dari pusat saja, hal diharapkan agar lingkungan kerja fisik senantiasa terjaga dan tidak mengganggu kinerja karyawan.

4. Komunikasi dan lingkungan kerja fisik hendaknya harus dijaga agar tidak terjadi masalah yang dapat menyebabkan terhambatnya kinerja perusahaan

5. Dengan melihat hasil penelitiaan bahwa komunikasi memiliki pengaruh dominan terhadap kinerja hendaknya perusahaan semakin meningkatkan komunikasi antar karyawan, karyawan dengan atasan agar kinerja semakin meningkat dengan melakukan upaya seperti pertemuan formal seperti rapat antar karyawan, antar atasan ataupun karyawan dengan atasan. 


\section{DAFTAR PUSTAKA}

Handoko, T. Hani. 2012. Manajemen Personalia dan Sumber Daya Manusia. Yogyakarta: BPFE

Suranto. 2010. Komunikasi Interpersonal. Yogyakarta. Graha Ilmu

Sedarmayanti.2009. Sumber Daya Manusia dan Produktivitas Kerja. Bandung: CV Mandar Maju

Hariandja, Marihot Tua Efendi, 2002, Manajemen Sumber Daya Manusia, Grasindo, Jakarta

Sugiyono. 2014. Metode Penelitian Pendidikan Pendekatan Kuantitatif, Kualitatif, dan R\&D. Bandung: Alfabeta.

Ghozali, Imam. 2013. Aplikasi Analisis Multivariate dengan Program IBM SPSS 21 Update PLS Regresi. Semarang: Badan Penerbit Universitas Diponegoro

Saydam, Gouzali. 2005. Manajemen Sumber Daya Manusia: Suatu Pendekatan Mikro. Jakarta: Djambaran 